\title{
Effectiveness of Agile Implementation Methods in Business Intelligence Projects from an End-user Perspective
}

\author{
Jerzy Kisielnicki and Anna Maria Misiak \\ Warsaw University, Warsaw, Poland
}

\author{
jkisielnicki@wz.uw.edu.pl; aniamisiak1@gmail.com
}

\begin{abstract}
The global Business Intelligence (BI) market grew by 10\% in 2013 according to the Gartner Report. Today organizations require better use of data and analytics to support their business decisions. Internet power and business trend changes have provided a broad term for data analytics Big Data. To be able to handle it and leverage a value of having access to Big Data, organizations have no other choice than to get proper systems implemented and working. However traditional methods are not efficient for changing business needs. The long time between project start and go-live causes a gap between initial solution blueprint and actual user requirements in the end of the project. This article presents the latest market trends in BI systems implementation by comparing Agile with traditional methods. It presents a case study provided in a large telecommunications company ( $20 \mathrm{~K}$ employees) and the results of a pilot research provided in the three large companies: telecommunications, digital, and insurance. Both studies prove that Agile methods might be more effective in BI projects from an end-user perspective and give first results and added value in a much shorter time compared to a traditional approach.
\end{abstract}

Keywords: Agile methods, Business Intelligence, efficiency, end-users needs, advanced analytics, sprint, and iteration.

\section{Introduction}

BI complexity and changing requirements represent the most difficult challenges facing applications. During the process of BI implementation multiple components must be considered from the very start such as data integration, cleansing, modelling, warehousing, metrics creation and management, reports, dashboards, queries, alerts, and many more (Cerqueira, 2015). This requires a clear vision of future needs and a very well defined strategy from project sponsors and end-users. Projects take a long time to implement and their effects can be visible sometimes only after a few years (Kernochan, 2011).

Material published as part of this publication, either on-line or in print, is copyrighted by the Informing Science Institute. Permission to make digital or paper copy of part or all of these works for personal or classroom use is granted without fee provided that the copies are not made or distributed for profit or commercial advantage AND that copies 1) bear this notice in full and 2) give the full citation on the first page. It is permissible to abstract these works so long as credit is given. To copy in all other cases or to republish or to post on a server or to redistribute to lists requires specific permission and payment of a fee. Contact Publisher@InformingScience.org to request redistribution permission.
Today organizations require BI solutions more than they needed them in previous years and decades. Due to rapid market changes, organizations need to adapt to the new environment properly if they do not want to stay behind their competitors. This situation impacts users' requirements for data and reports. Thus BI projects final products are often found useless due to organizational 
needs that have changed during the time of project design and implementation (Eckerson, 2007a, 2007b; Marjanovic, 2011). Business cannot longer afford empty investments and needs to have quick benefits and an acceptable payback on the selected BI technology (Oxford Economics, 2015).

Traditional methods of BI implementation are no longer efficient. An overly lengthy timeline, the inability to request timely changes that usually occur only at the end of the project, and overly complex approaches do not allow meeting customer targets (Vijaya, 2013). Agile methods brought a new view to a project delivery. It proves that success can be achieved more quickly by delivery of actual product in iteration.

In this article effectiveness is measured from the added value brought by $\mathrm{BI}$ in a short time (less than 6 months), namely return on investment achieved after the first BI benefits appear and by meeting end-users' requirements.

This article presents some initial research in order to answer the question, "Is Agile more efficient in BI implementation compared to traditional methods?"

\section{Agile vs. Traditional Implementation Approach}

For a better understanding of Agile methods for Business Intelligence (BI) system implementation projects, it is worth to compare Agile with the traditional / waterfall approach first.

Agile methods of implementation require a change of thinking and a different approach compared to traditional waterfall methods. Traditional methods concentrate on project scope using them to determine cost and time schedule. Agile concentrates on business values using them to determine quality levels and possible technology constraints. Where waterfall methods are suitable for wellarranged and predictable environments, Agile seems to be more appropriate for a somewhat chaotic and unstable environment, lacking a clear vision. All traditional models adopt the Rational Agent Model. Agile relies primarily on a so-called approach of shared values. Traditional methods use and create structures based on control; Agile structures are flat, collaborative, and based on mutual inspections (Evelson, 2010; Project Management \& Agile Methodologies, 2012; Vijaya, 2013). Table 1 shows a comparison of Agile to the traditional waterfall method:

Projects managed with Agile methods are provided in a progressive way, in iterations. As a result, products of a specific project are the actual functionalities of the system that may already be used by a user and organization. Firstly, the project delivers products that bring the most value for the business. Several teams work on different elements of the solution at the same time, so they can provide planned 'sprint / iteration' in a short time (Project Management \& Agile Methodologies, 2012). As a result, the number of unsupplied functionalities yet is reduced with the time of supplied iterations. Often with the traditional approach the number of not ready functionalities is high, until the end of the project. This means that every sprint represents a completed product (working functionality) delivered by a project team.

Traditional methods do not have those kinds of control points. In a waterfall scenario, often teams spend a long time on critical tasks leading the project progress to lag behind (due to the lengthening of project phases leading to the launching of the project) and end up with a long list of unfinished tasks at the end of the project.

Because of Agile team's iterations on successive versions of the product, they regularly engage the customers in the project and allow them to test additional versions of the product(s) or functionalities already being used in their daily work (Scott, 2012). 
Table 1. Comparison of Agile and Waterfall method.

(Awad, 2005; Project Management \& Agile Methodologies, 2012)

\begin{tabular}{|l|l|l|}
\hline \multicolumn{1}{|c|}{ Approach } & \multicolumn{1}{c|}{ Agile } & \multicolumn{1}{c|}{ Process } \\
\hline Emphasis & People & Predictable \\
\hline Domain & Unpredictability / Exploratory & Comprehensive \\
\hline Documentation & Minimal-only as required & Process centric \\
\hline Quality & Customer centric & Linear \\
\hline Process style & Iterative & Managed \\
\hline Organization & Self-organized & High \\
\hline Upfront planning & Low & Sustainable \\
\hline Perspective toward change & Adaptable & Fixed in the project plan \\
\hline Prioritization of requirements & Based on business value and regularly updated & Autocratic \\
\hline Management style & Decentralized & Command and control \\
\hline Leadership & Collaborative, Servant Leadership & Plan conformity \\
\hline Performance Measurement & Business value & End of project life \\
\hline Return of Investment & Early/throughout project life & \\
\hline
\end{tabular}

Moreover, Agile methods focus on delivering value and quality within the project development process. Traditional methods focus on the scope of the project and its schedule in order to remain within the determined project's budgeted cost and planned duration. Agile methods are constant in time, cost and quality - scope may not only change but is expected to change. In the case of traditional methods, scope is the constant factor of the project with the variables being time, cost and partially the quality of the delivered product. This is presented very well in Figure1:

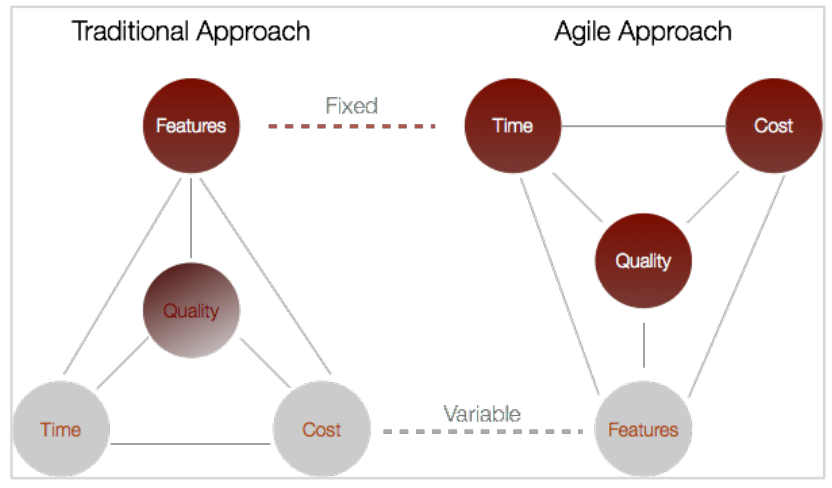

Figure 1. Comparison of the project triangles for traditional and Agile approaches (Awad, 2005; Beck et al., 2001)

In conclusion, it is important to indicate the main differences between Traditional and Agile project implementation management methods: 
1. In Agile methods cooperation with the customer takes place during the entire project on a regular basis, whereas in the Traditional ones, it is performed only at selected stages of the project.

2. In the Agile approach, changes are taken into account regardless of the stage of the project, whereas in the Traditional approach, changes are made only after the final acceptance of the solution concept.

3. The Agile project is divided into parts. Each section is treated as a final distinct product that can be used by customer and it can deliver return on investment already.

This paper focuses on usage of Agile implementation methods in BI implementation projects. The main reason behind it is the organisation's difficulty in having a clear view of the solution's shape and functionalities. This leads to many changes, often last minutes changes, required by users. This is not acceptable in Traditional methods while the Agile philosophy is based on it.

\section{Business Intelligence Market}

According to the Gartner report 2012), the global BI market grew by $10 \%$ in 2013. Only in 2012, growth was at $6.8 \%$ (compared to 2011 , an increase of $17 \%$ ), which was connected directly to the global economic crisis and a lack of trust in Big Data and new trends towards the development of BI Business Discovery (Oxford Economics, 2015).

The MIT Sloan Management SAS conducted a survey which showed that business analytics was a source of competitive advantage in 2012 as reported by $67 \%$ of companies. In 2011 , this percentage was $58 \%$ and the year before it was only $37 \%$.

Similar results were obtained by Oxford Economics (2015), which confirmed the research of MIT Sloan Management. Their analysis showed that currently $64 \%$ of surveyed executives believe that BI solutions provide growth and business development. Additional studies of Oxford Economics showed that for next three years, $69 \%$ of Polish companies would use BI tools, while business intelligence systems today are already used by $45 \%$ of companies. $35 \%$ of respondents claim that business intelligence can definitely improve cost control processes. Implementing such tools would bring an opportunity to improve products or services according to $34 \%$ of the respondents. Additionally, $21 \%$ of respondents believe that analytical software may increase the level of customer service.

As results from different data analytics and BI studies consistently show, for the last few years BI is a priority for decision-makers and managers of most businesses and institutions. Challenges for BI solutions are mainly with the pace of their development, and that development will need to keep up with data growth, both inside and outside the organization. Both the technology and the way the adaptation of BI in business will have to be increasingly flexible and easy to adapt by analysts and controllers. It also leads to new considerations about an "agile" approach to implementing BI solutions.

Yet in another study, according to a report of The Economist, Economist Intelligence Unit, Big Data (Giles, 2012):

1. There exists a strong relationship between financial results and effective use of Big Data,

2. Success can be achieved by those companies that focus on the priorities and strategy of their organizations by analysing data,

3. Technology can enrich an organization only when it successfully develops and adapts to changing environmental and business needs as fast as the rapidly changing market and data growth itself. 
4. BI must bring a new dimension to data management. Social-media websites have become an essential source of data; internal data are no longer sufficient.

\section{End-users' Perception of Business Intelligence (BI) Projects}

Developing interactive software tools is all about people. This is not only about end-users but about the development teams as well. Most software developers and designers deliver some sort of enhanced support for end-users and, as such, their knowledge about the users is crucial to the outcome of the project (Blomkvist, 2010). This importance was already stressed in 1991 by Liam Bannon:

"... more attention needs to be paid to the process of design, to working with users in all stages of design, to see the iterative nature of design, and challenging conception of what one is designing as a result of the process itself. This is in contrast to a view of design that proceeds from a set of fixed requirements without iterations, and without involvement of the users".

BI implementation projects might be very similar to software development projects. However, unlike application development, BI is an integration and configuration of commercial tools with customization occurring in the underlying data models and data manipulation "code" (ETL, SQL scripts, stored procedures, etc.). Instead of using object-oriented languages, BI requires stitching together many data sources and applications so that they work together seamlessly. However, in order to achieve this, proper technical designers and programmers must still be involved (Cerqueira, 2015; Parker, 2014).

As confirmed in the previous section Business Intelligence Market, BI systems are required more than ever by today's organizations. However the process of implementation still seems to struggle with achieving this objective.

A study by the Aberdeen Group (White, 2011) showed that "this style of BI is predominantly controlled, driven and delivered by corporate IT. Often, only static views of data are available and any changes or enhancements must be made by the IT-organization." This is no longer acceptable by today's organizations. Frequently changing business and big data market force companies to a quick response, which can be achieved by having timely and reliable information.

According to a Gartner Study based on BI end-users' interviews (Friedman, 2009) several problems appear during BI implementation:

1. A long development lifecycle and less visibility to user.

2. Users are not involved in development cycles.

3. After the design phase there is no possibility to modify analytical requirements.

4. Testing is at the end of the development cycle, again without a possibility for change requests.

5. A different language: the developers think in terms of code, the business thinks in terms of business value and solution designers think in terms of customer experience.

A possible solution to these problems could be the use of Agile methods. One Agile method is called Active Stakeholder Participation (ASP), an expansion of eXtreme Programming (XP)'s On-Site Customer. It describes the need to have on-site access to people, typically users or their representatives, who have the authority and ability to provide information pertaining to the system being built and to make pertinent and timely decisions regarding the requirements and prioritization. This approach seems to be very suitable for BI implementation projects. 
People are not very good at defining, particularly in detail, what they want. Especially when it comes to reports or dashboards. However, people are good at indicating what they think they want and then when a particular option is presented to them, what they like and do not like about it. That means that daily work with end-users would help to identify what they think, what they want, produce something which reflects that understanding, obtain feedback from them, and then update the solution to reflect an improved understanding.

Traditional approaches to software development that are based on defining a detailed requirements' specification early in the project, referred to as "big requirements up front (BRUF)" strategies, prove to be very risky in practice. Traditional project teams, even "successful" ones, typically produce less than ideal results when they strive to produce a solution, which reflects the specification (Awad, 2005; Project Management \& Agile Methodologies, 2012; Scott, 2012). Traditional project teams may produce something to specification, but it likely will not be what the users actually want, but rather something what they thought they needed at some point in the past. The goal of a disciplined Agile delivery project team should be to provide their end users with a solution that fulfils their current understanding of the intent of their users as effectively as possible, given the constraints of the situation.

\section{Efficiency of BI Implementation with Agile Methods}

\section{Case Study in a Telecommunications Company}

BI systems can consist of different tools and components, depending on the level and purpose of usage. Thus, there are many ways of BI systems' classification that can be found in the professional literature. Chen, Chiang, and Storey in 2012, classified BI by the type of data processed:

Table 2. BI\&A evolution: Key Characteristics and Capabilities (Chen et al., 2012)

\begin{tabular}{|l|l|ll|}
\hline & \multicolumn{1}{|c|}{ Characteristic } & \multicolumn{1}{c|}{ Feature } \\
\hline BI\&A 1.0 & Data-centric approach & $\bullet$ & DBMS - data based on columns \\
& & $\bullet$ & In-memory DBMS \\
& & $\bullet$ & Real-time decisions \\
& & $\bullet$ & Data mining workbenches \\
\hline BI\&A 2.0 & Web-based technology & $\bullet$ & Opinion mining \\
& & $\bullet$ & Answers to questions with normal language \\
& & $\bullet$ & Web- analytics \& web intelligence \\
& & $\bullet$ & Social media analytics \\
& & $\bullet$ & Incorporation of unstructured data into its \\
& Mobile \& sensor technology BI & $\bullet \quad$ Location-aware analysis \\
& & $\bullet \quad \begin{array}{l}\text { Person-centered analysis } \\
\text { BI\&A 3.0 }\end{array}$ & $\bullet \quad$ Context-relevant analysis \\
& & $\bullet$ & Mobile visualisation \& HCI \\
\hline
\end{tabular}

Depending on the type of BI, methods of BI implementation might vary. In the following case study and survey, the BI belongs to BI\&A 2.0, web based technology, according to Chen et al.'s (2012) classification.

This research has been conducted in a telecommunications company upon their request and due to an initiative they were engaged in for the preparation of controlling processes transformation. Currently, the report is available for internal, company's usage. The company has $20000 \mathrm{em}-$ ployees and is one of the major players in the fixed and mobile services in both the local and 
global market. For the last couple of years, the company merged, sold, and acquired many enterprises having similar or related profiles. These kinds of changes are typical for large businesses. Obviously this has many IT-related consequences, like mixed application architecture, complex business processes, and different data sources. The surrounding market is growing new competitors. The telecommunications company started facing serious problems due to a lack of good market analysis and valuable insight data and reports. Thus, the company decided to optimize its controlling processes by one data warehouse \& BI implementation. The warehouse and BI were linked to 300 different data sources. In order to demonstrate the scale of the data integration, it was estimated that annually, the company produces 20 million lines of transactions in the general ledger alone.

Before the project started, the company calculated around 1000 reports were produced for different business areas at operational levels and management levels. Taking the Traditional approach to project implementation, it was evaluated that most probably it would not bring value quickly. Identification of the scope was difficult due to the business case challenges (e.g., too expensive infrastructure, not enough employees with required skills, etc.). The company decided not to copy the same information flows and reports and to start instead from the beginning. To meet these expectations, it was decided to manage the project using the Agile method. This way the actual time spent was happening only with a released product, decreasing risk of failure associated with typical project phases implementation found in the traditional approach, and elaborated above.

\section{How the company arranged the project}

BI users dedicated $50 \%$ of their daily work to the project. Project Management initially built five parallel working teams, which consisted with staff from:

- Sales - three teams focusing on three product lines;

- Purchasing - one team from the procurement system;

- Finance - one team from accounting system.

Teams were having typical Agile - Scrum members: Product Owner, Scrum Master and development members (usually 3 people). All teams worked separately on some functionality deliverables. Some deliverables required linkage between teams. That was the role of Business Visionary and Project Manager.

Teams followed Agile principles and methods based on user stories (instead of traditional requirements of report formats), prioritization method MoSCoW (Must, Should, Could, Won't), daily stand-ups and regular cooperation and verification of requirements. With this approach, at the end of the project, the company declared it was a success.

\section{Results of the first year BI project implementation}

During the first year, teams produced eight different products related to data analysis of the customer market in three business areas of products. The total investment within one year was $10 \%$ of the estimated cost of the project if the traditional approach was taken. The company managed to eliminate 170 useless reports, which were produced before BI functionality delivery. This improved controlling processes by 15 FTE (Full Time Employee).

Table 3: ROI factors result.

\begin{tabular}{|c|l|}
\hline Cost of current vs. future system maintenance & $150 \%$ decrease in annual maintenance \\
\hline $\begin{array}{c}\text { Total cost of FTEs involved in the current vs. future } \\
\text { reporting process }\end{array}$ & 15 FTEs reduced \\
\hline $\begin{array}{c}\text { Cost of time spend on the current vs. future reporting } \\
\text { process }\end{array}$ & $50 \%$ decrease of reporting time \\
\hline
\end{tabular}


ROI was calculated only for a one year investment in order to provide a prototype solution for the company (see Table 3). End-user expectations have been met, and the first delivered product is in use. The company continues working on further implementation. However, the first year was crucial to see whether the Agile approach and BI investment will bring any value.

Twenty end-users (middle management and operational level) were asked for the main reasons of success in a survey following Agile principles. Results confirmed all Agile principles as elaborated in Table 4.

Table 4: Agile principles in context of BI users.

\begin{tabular}{|c|c|}
\hline Agile Principle & BI Response \\
\hline $\begin{array}{l}\text { Customer satisfaction due to early and } \\
\text { continuous delivery of valuable software }\end{array}$ & $\begin{array}{l}\text { Due to the fact that BI users have a chance to see a product } \\
\text { already after few weeks, it is easier to make sure that the pro- } \\
\text { ject is meeting the requirements. }\end{array}$ \\
\hline $\begin{array}{l}\text { Welcome changing requirements, even in } \\
\text { late development }\end{array}$ & $\begin{array}{l}\text { During the project, end-users requirements changes and it is } \\
\text { not possible to avoid it. Especially in the environment like } \\
\text { reports and data. Data is increasing in incredible fast way } \\
\text { which impact new required sources and new analytics. By } \\
\text { agreeing to these changes, a project meets customer expecta- } \\
\text { tions }\end{array}$ \\
\hline $\begin{array}{l}\text { Working software is delivered frequently } \\
\text { (weeks rather than months) }\end{array}$ & $\begin{array}{l}\text { End-user has a chance to verify and challenge requirements } \\
\text { on regular basis. }\end{array}$ \\
\hline $\begin{array}{l}\text { Close, daily cooperation between business } \\
\text { people and developers }\end{array}$ & $\begin{array}{l}\text { Constant, daily end-user involvement helps the project to fol- } \\
\text { low actual business needs and changes, which may impact the } \\
\text { solution. }\end{array}$ \\
\hline $\begin{array}{l}\text { Projects are built around motivated indi- } \\
\text { viduals, who should be trusted }\end{array}$ & $\begin{array}{l}\text { Best, involvement of committed people always helps to ob- } \\
\text { tain success }\end{array}$ \\
\hline $\begin{array}{l}\text { Face-to-face conversation is the best form } \\
\text { of communication (co-location) }\end{array}$ & $\begin{array}{l}\text { End-users are committed and cooperative when the commu- } \\
\text { nication process is performed properly. }\end{array}$ \\
\hline $\begin{array}{l}\text { Working software is the principal measure } \\
\text { of progress }\end{array}$ & $\begin{array}{l}\text { Working software means that users can actually work on it } \\
\text { and test it. That helps end-users follow the project by seeing } \\
\text { actual development and estimate its progress. }\end{array}$ \\
\hline $\begin{array}{l}\text { Sustainable development, able to maintain } \\
\text { a constant pace }\end{array}$ & $\begin{array}{l}\text { This way there is no rush and possible mistakes in the product } \\
\text { delivery. }\end{array}$ \\
\hline $\begin{array}{l}\text { Continuous attention to technical excel- } \\
\text { lence and good design }\end{array}$ & These are factors always required by end-users. \\
\hline $\begin{array}{l}\text { Simplicity - the art of maximizing the } \\
\text { amount of work not done-is essential }\end{array}$ & $\begin{array}{l}\text { Simple solutions especially in BI projects, help users to un- } \\
\text { derstand and use the new functions better. At the same time, it } \\
\text { might be easier to provide a change, if required. }\end{array}$ \\
\hline Self-organizing teams & $\begin{array}{l}\text { The customer as a part of a team, takes responsibility for } \\
\text { working, valuable data and reports. May impact the daily } \\
\text { work and feed info on regular basis. At the same time cooper- } \\
\text { ation is more efficient by eliminating any walls between cus- } \\
\text { tomer and vendor. }\end{array}$ \\
\hline $\begin{array}{l}\text { Regular adaptation to changing circum- } \\
\text { stance }\end{array}$ & $\begin{array}{l}\text { This point is one of the most important for BI users. Need for } \\
\text { reports, information and data sources might change often. } \\
\text { Thus thanks to all of the above principles; users can deliver } \\
\text { actual requirements and possible changes. }\end{array}$ \\
\hline
\end{tabular}




\section{End-users Perspective of Agile and Waterfall Methods of BI implementation}

Additionally, to the case study presented in the previous section, the following pilot research shows that the Agile method of BI systems implementation is more efficient from the end-user's perspective. This initial study (Misiak, 2015) will be followed by further research, which will be published in materials available at the Warsaw University of Technology.

A method of research has been based on surveys and interviews in the following three service companies:

1. A telecommunications company, described above, where BI was implemented following the Agile method.

2. A digital company (specialized in mobile software and video production) with a subsidiary, 10000 employees, where BI was implemented following the traditional method.

3. An insurance company (offering many types of insurance for individual and business customers), 17000 employees, where BI was implemented using the traditional method.

In total, there were $65 \mathrm{BI}$ end-users who responded to the survey and were interviewed. Fifteen BI users (Agile $\mathrm{N}=15$ ) experienced implementation with the Agile method, $50 \mathrm{BI}$ users (Waterfall $\mathrm{N}=50$ ) experienced implementation with the waterfall method. Figures 2 and 3 present the results of the survey.

Figures 2 and 3 show the pilot results of the survey. It confirms Agile effectiveness in BI projects by the following: achieved an ROI and fast BI solution availability and end-user's satisfaction in terms of functionality and actual BI help in their work. However, at the same time, results of the BI system's implementation with Traditional methods show that goals were not achieved. Causes include lengthy time of solution delivery and a less flexible product at the end of implementation. This is a small sample taken into consideration though. However, it is a meaningful sample due to the size of the organizations and their position in the market.

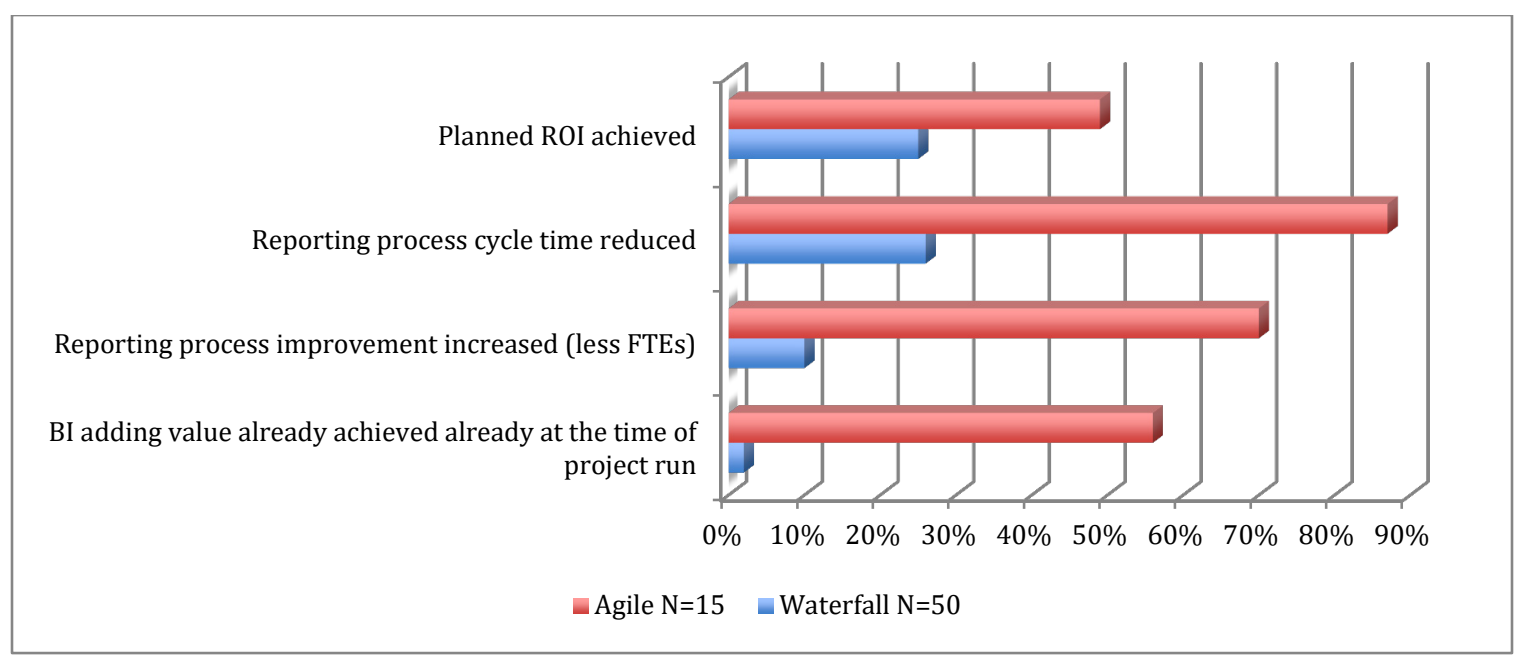

Figure 2: BI investment completion according to the prior assumptions. 


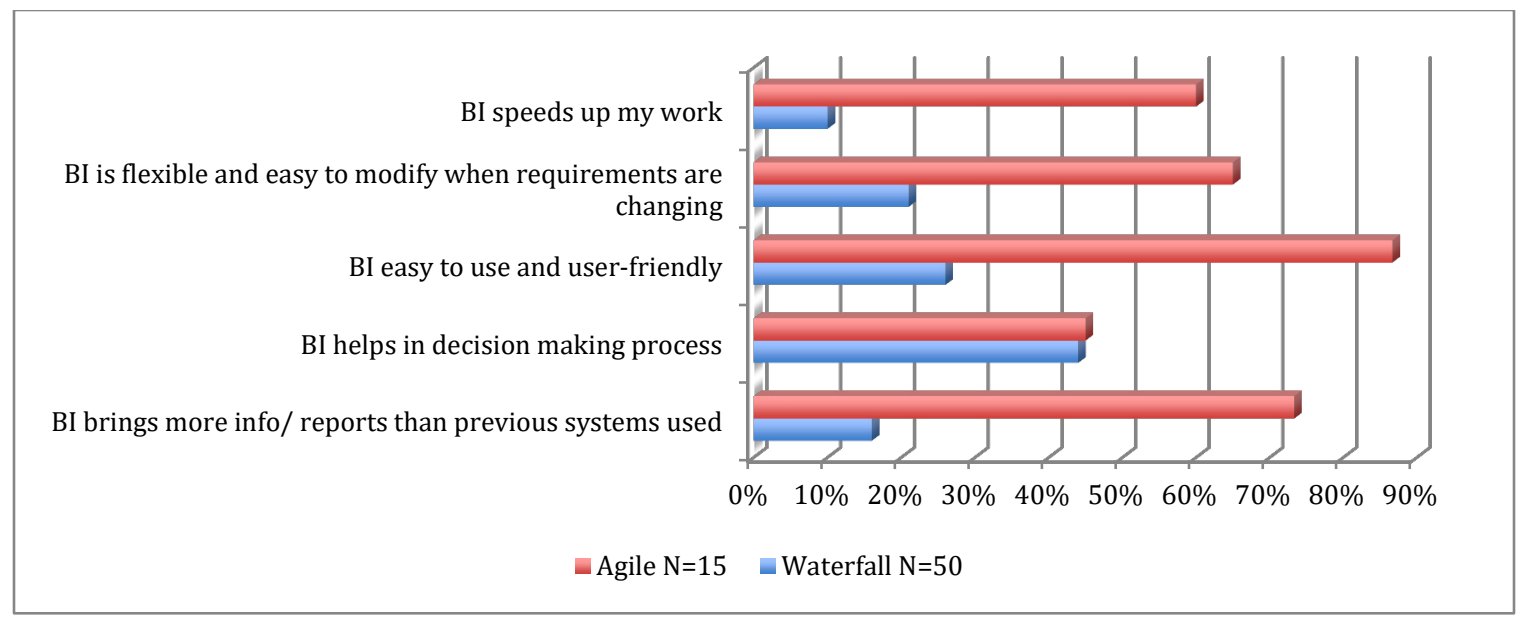

Figure 3: Level of requirements met by the BI implementation.

\section{Conclusion}

Currently, Business Intelligence systems are the most required systems in the market. However, organizations continue to struggle with the decision to implement them in their environment. Changing markets and big data insight forces organizations to react quickly, especially due to growing competition. However, to meet customer's requirements, BI methods of implementation need to change from a traditional waterfall method to an Agile approach. The study in this article presents the benefits of Agile methods especially in the area of user's constant involvement and delivery in iterations. Today business cannot wait long for the first results of a system's implementation. It can be achieved only thanks to a few main critical factors:

- Easy adaptability to changes when required,

- Frequent functionalities delivery,

- Fast ROI,

- Easy and cost-effective maintenance after BI implementation.

The Agile approach provides methods and techniques to meet these above factors. As the case study and surveys show, end-users find BI more valuable when it is implemented using the Agile method. It helps to achieve the goal and effective BI implementation. It helps to provide not only reliable data and good analysis but at the same time to optimize the process and increase added value.

The presented study is based on few companies, similar in terms of company size and type. Thus, it will be followed will be followed by further research, which will be published in materials available at the Warsaw University of Technology.

\section{References}

Awad, M. A. (2005). A comparison between agile and traditional software development methodologies. School of Computer Science and software Engineering, The University of Western Australia, 2005.

Bannon, L. (1991): Comments from the sidelines: Some thoughts on research networks and network research. Behaviour and Information Technology, 10(3), 253-256.

Beck, K., Beedle, M., van Bennekum, A., Cockburn, A., Cunningham, W., Fowler, M., ... Grenning, J. (2001). Principles behind the Agile Manifesto. Retrieved January 2016 from www.agilemanifesto.org/principles.html 
Blomkvist, S. (2010). Towards a model for bringing agile development and user-centered design. Uppsala University, Sweden

Cerqueira, P. (2015). Lessons learned supporting a large-scale, real-world production data warehouse/business intelligence environment. Business Intelligence Journal, 20(4).

Chen, H., Chiang, R. H. L., \& Storey, V. C. (2012). Business intelligence and analytics: From big data to big impact. MIS Quarterly, 36(4), 1165-1188.

Eckerson W. (2007a). Predictive analytics. Extending the value of your data warehousing investment. TDWI Best Practices Report. Retrieved June 2013 from https://www.sas.com/events/cm/174390/assets/102892_0107.pdf

Eckerson W. (2007b). The secrets of creating an Agile adaptable BI environment. TDWI Education. Retrieved March 2011 from http://tdwi.org/webcasts/2007/07/the-secrets-of-building-an-agile-adaptablebi-environment.aspx

Evelson B. (2010). Agile BI out of the box. Retrieved March 2010 from https://www.wherescape.com/media/1235/agile-bi-out-of-the-box.pdf

Friedman, T. (2009). Gartner says more than 50 percent of data warehouse projects will have limited acceptance or will be failures through 2007. 2005.

Gartner Report. (2013). Gartner says worldwide business intelligence, CPM and analytic applications/performance management software market grew seven percent in 2012. Retrieved June 2013 from www.gartner.com/newsroom/id/2507915

Giles, J. (2012). Big data: Lessons from the leaders. Economist Intelligence Unit. The Economist. Available at https://www.sas.com/resources/asset/EIU_SAS_BigData_120822.pdf

Kernochan, W. (2011). Why most business intelligence projects fail. Retrieved from http://www.enterpris1appstoday.com/business-intelligence/why-most-business-intelligence-projectsfail-1.html

Marjanovic, O. (2010). Business value creation through business processes management and operational business intelligence integration. Retrieved May 2015 from:

http://ieeexplore.ieee.org/xpl/login.jsp?tp=\&arnumber=5428535\&url=http\%3A\%2F\%2Fieeexplore.iee e.org\%2Fxpls\%2Fabs_all.jsp\%3Farnumber\%3D5428535

Misiak, A. M. (2015). Agile method of BI systems implementation. [research paper]. Faculty of Management, Warsaw University of Technology, September 2015

Oxford Economics. (2015). Digital Megatrends 2015: The role of technology in the new normal market. Retrieved May 2015 from https://www.oxfordeconomics.com/Media/Default/Thought\%20Leadership/advisorypanels/Digital_Megatrends.pdf

Parker, J. (2014). KPIs for agile project managers and business analysts. Retrieved January 2016 from http://www.slideshare.net/EnfocusSolutions/kpis-for-agile-project-managers-and-business-analysts

Project Management \& Agile Methodologies. (2012). Retrieved from https://www.cprime.com/2012/09/project-management-agile-methodologies

Scott, W. (2012). Active stakeholder participation: An agile best practice. Retrieved January 2016 from http://agilemodeling.com/essays/activeStakeholderParticipation.htm\#Why

Vijaya, D. (2013). Traditional and agile methods: An interpretation. Retrieved January 2013 from https://www.scrumalliance.org/community/articles/2013/january/traditional-and-agile-methods-aninterpretation

White, D. (2011). Agile BI: Completing traditional BI to address the shrinking decision-window. Aberdeen Group. Retrieved December 2015 from: http://www.blockconsulting.net/PSBDGroup/Aberdeen-agileBI-shrink-decision-window.pdf 


\section{Biographies}

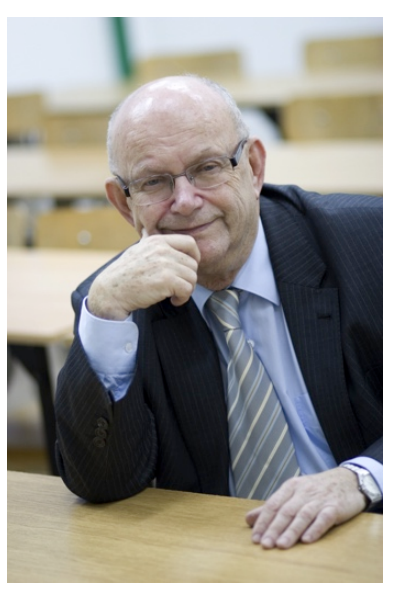

Jerzy Kisielnicki professor of management has been the head of the Department of Information Systems in Management and Faculty of Management at Warsaw University.

His interests are organization and management, systems analysis, management information systems, e-learning, process innovation (reengineering), strategic management, and transition systems organization and management in market economy. Dr. Kisielnicki is a member of the Board of Organization and Management in Polish Academy of Science and is the head of the Scientific Council of Polish Society of Systems Information. He has had about 220 publications. He was involved and led many ICT projects.

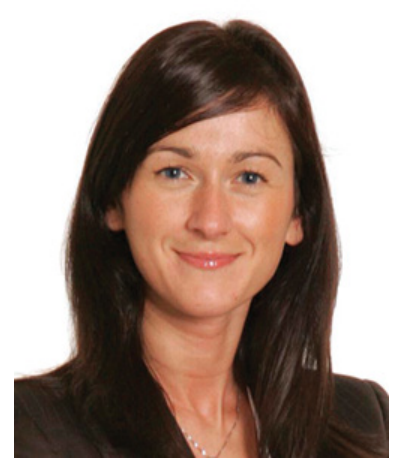

Anna Maria Misiak PhD student at the University of Technology, Department of Information Systems in Management. Her current area of research is focusing on factors impacting the process of preparing organizations to Business Intelligence implementation.

Her research interests include organization transformations, reengineering processes, system analysis, implementation of management systems and project management. She is working as an independent consultant responsible for business applications' integration. She has been involved in many projects of mergers and acquisitions. This experience is the research base to her publications and the $\mathrm{PhD}$ Thesis. 